\title{
Chronic Obstructive Pulmonary Disease (COPD)
}

\author{
Mona Z Zaghloul* \\ Microbiology Unit, Department of Clinical Pathology, Ain Shams University Hospitals, Cairo, Egypt
}

*Corresponding author: Zaghloul MZ, Ain Shams University Hospitals, Cairo, Egypt, Tel: 02-24023494; E-mail: monazaki_810@hotmail.com

Received date: September 24, 2015, Accepted date: September 30, 2015, Published date: October 5, 2015

Copyright: (c) 2015 Zaghloul MZ. This is an open-access article distributed under the terms of the Creative Commons Attribution License, which permits unrestricted use, distribution, and reproduction in any medium, provided the original author and source are credited

\section{Editorial}

Chronic obstructive pulmonary disease (COPD) is an inflammatory disease characterized by progressive decline in lung function accompanied by airway narrowing due to inflammation, fibrosis and mucus plugging, associated by parenchymal destruction with loss of elasticity, gas exchange surface area, and airway support with subsequent early airway closure [1]. COPD affects more than 400 million people worldwide. The prevalence rate of COPD is highly variable ranging from $0.2 \%$ in Japan to $37 \%$ in the United States. According to the 12-site Burden of Obstructive Lung Disease (BOLD) study, the average prevalence of COPD is $10.1 \%$, with wide variations [2]. COPD is predicted to become the fourth leading cause of death and the fifth commonest cause of disability in the world by 2030 [3].

Tobacco smoking and environmental pollution are the most well known risk factors for COPD. Most patients presented by dyspnea and exercise intolerance due to deranged lungs and impaired peripheral oxygenation to the skeletomuscular system and mitochondria [4]. The progressive course of COPD is accelerated by acute exacerbations, which are episodes of worsening of symptoms, which are the most frequent cause of hospitalizations and death among COPD patients $[5,6]$. Evidence suggests that $\geq 50 \%$ of acute exacerbations are due to bacteria requiring treatment with an antibiotic which should have high activity against the causative pathogens [7].

Patients with abnormal pulmonary inflammation characterized by increased number of inflammatory cells (neutrophils, macrophages, and T-lymphocytes) and the release of multiple inflammatory mediators such as: lipids, chemokines, cytokines, and growth factors $[8,9]$. The involvement of genetic factors in the pathogenesis of COPD was proved through the observation that individuals with severe deficiency for alpha-1-antitrypsin, a major inhibitor of serine proteases, have an increased risk of developing COPD [10]. The main causes of deaths in COPD patients were cardiovascular diseases (mainly heart attack and stroke), exacerbations and lung cancer (more than $75 \%)$ [11].

A diagnosis of COPD should be considered in persons having chronic symptoms of cough, sputum production, shortness of breath, and/or wheezing, especially among those with prolonged exposure to risk factors for the disease. Forced expiratory time (FET) of more than six seconds is suggestive of airflow obstruction [12]. Also significant decreased superoxide dismutase 3 and increased ferroxidase activity, surfactant protein $\mathrm{D}$, glutathione peroxidase, and $\mathrm{C}$-reactive protein levels were found in subjects with COPD [13]. Triple combination therapy involving long-acting muscarinic antagonists long-acting $\beta 2$ agonists, and inhaled corticosteroids has recently become an option for maintenance treatment of COPD [14]. Rhodiola crenulata has been shown to exert anti-inflammatory effects and to enhance exercise endurance thereby having the potential to treat COPD [15].

\section{References}

1. Hogg JC, Timens W (2009) The pathology of chronic obstructive pulmonary disease. Annu Rev Pathol 4: 435-459.

2. Buist AS, McBurnie MA, Vollmer WM, Gillespie S, Burney P, et al. (2007) International variation in the prevalence of COPD (the BOLD Study): a population-based prevalence study. Lancet 370: 741-750.

3. Mathers CD, Loncar D (2006) Projections of global mortality and burden of disease from 2002 to 2030. PLoS Med 3: e442.

4. Chuang ML, Lin IF (2014) Clinical characteristics and lung function in chronic obstructive pulmonary disease complicated with impaired peripheral oxygenation. Intern Emerg Med 9: 633-640.

5. Sialer S, Adamantia L, Guerrero M, Torres A (2012) Relation between chronic obstructive pulmonary disease and antibiotics. Curr Infect Dis Rep 14: 300-307.

6. Suissa S, Dell'Aniello S, Ernst P (2012) Long-term natural history of chronic obstructive pulmonary disease: severe exacerbations and mortality. Thorax 67: 957-963.

7. Wilson R, Sethi S, Anzueto A, Miravitlles M (2013) Antibiotics for treatment and prevention of exacerbations of chronic obstructive pulmonary disease. J Infect 67: 497-515.

8. Barnes PJ (2000) Mechanisms in COPD: differences from asthma. Chest 117: $10 \mathrm{~S}-4 \mathrm{~S}$

9. Chung KF (2006) Cytokines as targets in chronic obstructive pulmonary disease. Curr Drug Targets 7: 675-681.

10. Wei L, Xu D, Qian Y, Huang G, Ma W, et al. (2015) Comprehensive analysis of gene-expression profile in chronic obstructive pulmonary disease. Int J Chron Obstruct Pulmon Dis 10: 1103-1109.

11. PÅ,ywaczewski R, Maciejewski J, Bednarek M, ZieliÅ,ski J, GÃ $\tilde{3}^{3}$ recka D, et al. (2015) Causes of deaths in COPD patients in primary care setting--a 6-year follow-up. Pneumonol Alergol Pol 83: 193-202.

12. Gupta D, Agarwal R, Aggarwal AN, Maturu VN, Dhooria S, et al. (2013) Guidelines for diagnosis and management of chronic obstructive pulmonary disease: Joint ICS/NCCP (I) recommendations. Lung India 30: 228-267.

13. Ambade VN, Sontakke AN, Barthwal MS, Tyagi R, Basannar DR (2015) Diagnostic Utility of Biomarkers in COPD. Respir Care .

14. Miyazaki M, Nakamura H, Takahashi S, Chubachi S, Sasaki M, et al. (2015) The reasons for triple therapy in stable COPD patients in Japanese clinical practice. Int J Chron Obstruct Pulmon Dis 10: 1053-1059.

15. Chuang ML, Wu TC, Wang YT, Wang YC, Tsao TC, et al. (2015) Adjunctive Treatment with Rhodiola Crenulata in Patients with Chronic Obstructive Pulmonary Disease - A Randomized Placebo Controlled Double Blind Clinical Trial. PLoS One 10: e0128142. 